\title{
Aspectos microbiológicos e físico-químicos de morango exposto ao gás ozônio em diferentes concentrações durante o armazenamento
}

\author{
Microbiological and physical-chemical aspects of strawberry \\ exposed to ozone gas at different concentrations during storage
}

\author{
Hanna Alves ${ }^{1}$, Ernandes Rodrigues de Alencar ${ }^{1 *}$ (1), Wallas Felippe de Souza Ferreira ${ }^{1}$, \\ Caroline Rosa da Silva ${ }^{1}$, Jaqueline Lamounier Ribeiro ${ }^{1}$ \\ ${ }^{1}$ Universidade de Brasília (UnB), Faculdade de Agronomia e Medicina Veterinária (FAV), Brasília/DF - Brasil \\ *Corresponding Author: Ernandes Rodrigues de Alencar, Universidade de Brasília (UnB), Faculdade de \\ Agronomia e Medicina Veterinária (FAV), Campus Darcy Ribeiro, Asa Norte, CEP: 70910-900, Brasília/DF - Brasil, \\ e-mail: ernandesalencar@unb.br
}

Cite as: Alves, H., Alencar, E. R., Ferreira, W. F. S., Silva, C. R., \& Ribeiro, J. L. (2019). Microbiological and physical-chemical aspects of strawberry exposed to ozone gas at different concentrations during storage. Brazilian Journal of Food Technology, 22, e2018002, https://doi.org/10.1590/1981-6723.00218

\begin{abstract}
Resumo
Objetivou-se com este trabalho avaliar aspectos microbiológicos e físico-químicos de morangos da variedade Portola, expostos ao gás ozônio em diferentes concentrações e armazenados durante seis dias sob refrigeração. Foram avaliadas concentrações do ozônio equivalentes a 0, 4, 9, 14 e $18 \mathrm{mg} \mathrm{L}^{-1}$, vazão de $1 \mathrm{~L} \mathrm{~min}^{-1}$, na temperatura de $25^{\circ} \mathrm{C}$, por $30 \mathrm{~min}$. No que tange à qualidade microbiológica, avaliou-se a presença de Salmonella spp. e quantificaram-se coliformes totais, E. coli, bolores e leveduras, e mesófilos aeróbios. Com relação à qualidade físicoquímica, analisaram-se perda de massa, acidez total titulável, sólidos solúveis totais, $\mathrm{pH}$, relação sólidos solúveis totais e acidez total titulável, além da coloração dos frutos. Adotou-se Delineamento Inteiramente Casualizado em Esquema Fatorial $5 \times 4$, sendo cinco tratamentos e quatro períodos de armazenamento $(0,2,4$ e 6 dias), com três repetições. Não foi detectada a presença de Salmonella spp. nos frutos submetidos ou não à ozonização. Quanto à E. coli, a contagem foi inferior ao limite de detecção. A baixa e irregular contagem de coliformes totais nos frutos não permitiu inferir sobre a capacidade do ozônio de inativar microrganismos desse grupo. $O$ ozônio se mostrou eficiente no controle de bolores e de leveduras, e de mesófilos aeróbios em morangos, durante o armazenamento. De maneira geral, o ozônio não afetou negativamente a qualidade físico-química dos morangos. Por outro lado, verificou-se menor perda de massa nos frutos ozonizados quanto maior a concentração de exposição ao gás. Concluiu-se que o ozônio é um importante agente antimicrobiano e, nas condições adotadas no trabalho, provocou redução de microrganismos indesejáveis. Em geral, o ozônio não interferiu nas variáveis físico-químicas avaliadas.
\end{abstract}

Palavras-chave: Fragaria × ananassa Duch.; Ozonização; Qualidade microbiológica; Qualidade físico-química; Armazenamento; Conservação. 


\begin{abstract}
The objective of this work was to evaluate microbiological and physical-chemical quality of strawberries, Portola variety, exposed to ozone gas at different concentrations and stored for six days under refrigeration. Ozone concentrations equivalent to $0,4,9,14$ and $18 \mathrm{mg}^{\mathrm{L}} \mathrm{L}^{-1}$, flow rate of $1 \mathrm{~L} \mathrm{~min}^{-1}$, at $25^{\circ} \mathrm{C}$, were evaluated for $30 \mathrm{~min}$. Regarding microbiological quality, the presence of Salmonella spp. was evaluated, and total coliforms, E. coli, molds and yeasts and aerobic mesophiles were quantified. Regarding the physical-chemical quality, the following parameters were evaluated: mass loss, titratable total acidity, total soluble solids, $\mathrm{pH}$, total soluble solids ratio, besides the color of the fruits. Completely Randomized Design was used in Factorial Scheme $5 \times 4$, with five treatments and four storage periods $(0,2,4$ and 6 days), with three replications. No presence of Salmonella spp. was detected in fruits submitted or not to ozonation. For E. coli, the count was below the detection limit. The low and irregular count of total coliforms in the fruits did not allow inferring about the ozone capacity to inactivate microorganisms of this group. Ozone was effective in controlling mold and yeast and aerobic mesophiles in strawberries during storage. In general, ozone did not affect negatively the physical-chemical quality of strawberries. On the other hand, it was observed that, the higher the gas concentration, the lower was the fruits loss of mass. It was concluded that ozone is an important antimicrobial agent, and there was a reduction of undesirable microorganisms under the adopted conditions in this work. In general, ozone did not interfere with the evaluated physical-chemical variables.
\end{abstract}

Keywords: Fragaria x ananassa Duch.; Ozonation; Microbiological quality; Physical-chemical quality; Storage; Conservation.

\title{
1 Introdução
}

Os frutos do morangueiro (Fragaria $\times$ ananassa Duch.) são altamente perecíveis devido à sua composição química; além disso, devem percorrer uma cadeia produtiva, entre a colheita e o consumo, com, no máximo, uma semana, em ótimas condições, as quais muitas vezes não se verificam nas operações reais. Um dos fatores que colaboram para essa curta vida de prateleira - entre 5 e 7 dias - são os microrganismos deteriorantes, a alta taxa respiratória dos frutos, assim como as condições de armazenamento e temperaturas inadequadas (Aguayo et al., 2006; Nascimento \& Silva, 2010). Sua fragilidade demanda cuidados nas fases de colheita, manuseio, armazenamento, transporte, processamento e comercialização, devido aos danos mecânicos, microbiológicos e fisiológicos que podem comprometer a qualidade do fruto (Ponce et al., 2010).

Microrganismos, como aeróbios mesófilos, do grupo coliformes, bolores e leveduras, são encontrados geralmente em produtos in natura e minimamente processados, em concentrações que variam de $10^{3}$ a $10^{9} \mathrm{UFC} \mathrm{g}^{1}$, sendo responsáveis tanto pela deterioração da qualidade físico-química como pelo risco à saúde dos consumidores (Tournas \& Katsoudas, 2005; Abadias et al., 2008; Alexandre et al., 2011; Pang \& Hung, 2016). Nesse contexto, o morango esteve associado a surtos de hepatite A, além de contaminação por Norovírus, Cyclospora cayatanensis e Staphylococcus aureus (Notermans et al., 2004; Sivapalasingam et al., 2004).

Diversos sanitizantes são utilizados na indústria alimentícia para frutas e hortaliças, porém, cada vez mais, é preciso introduzir produtos que se adequem à nova realidade exigida pelo mercado. Além de exigir um alimento seguro, que não ocasione danos à saúde, o mercado consumidor busca produtos que sejam produzidos em sistemas sustentáveis, consciência que cresce cada vez mais, principalmente quanto ao uso racional da água (Chiattone et al., 2008). Dentre os sanitizantes mais utilizados na indústria de alimentos, para fins de higienização, incluem-se os compostos clorados. Todavia, estes produtos vêm sofrendo restrições quanto à sua utilização, devido à formação de subprodutos altamente tóxicos e cancerígenos, como os compostos organoclorados, tri-halometanos (THMs) e ácidos haloacéticos, quando aplicados em materiais orgânicos, além de o cloro ser considerado corrosivo para alguns materiais constituintes dos equipamentos. Outro fator é a observada resistência à ação do cloro de esporos bacterianos e oocistos de protozoários (Silva et al., 2011; Coelho et al., 2015). 
É de extrema importância o estudo de alternativas ao cloro que sejam eficientes na inativação de microrganismos e que não afetem a qualidade físico-química dos produtos, assim como a saúde dos consumidores. A ozonização tem sido proposta como alternativa para a preservação da qualidade pós-colheita de produtos de origem vegetal. É considerada uma técnica segura, sendo que o ozônio apresenta elevada capacidade de decomposição e não gera resíduos tóxicos, além de ser um potente agente antimicrobiano. Destaca-se que o ozônio foi classificado como GRAS (Generally Recognized as Safe) nos Estados Unidos e é liberado pelo FDA (Food and Drug Administration, 2001) para uso em alimentos, como agente antimicrobiano.

O gás ozônio ou oxigênio triatômico, forma alotrópica do oxigênio, é um potente agente oxidante e sua utilização na agricultura se torna atraente pelo fato de poder ser gerado no próprio local de aplicação, na forma gasosa ou dissolvido em água, e o produto de sua degradação ser o próprio oxigênio $\left(\mathrm{O}_{2}\right)(\mathrm{Graham}$, 1997; Kim et al., 1999; Mendez et al., 2003; Güzel-Seydim et al., 2004; Food and Drug Administration, 2013). O ozônio gasoso tem demonstrado expressiva eficácia na descontaminação de frutas e hortaliças, de equipamentos industriais, de superfícies que entram em contato com alimentos, no tratamento de água e de efluentes, entre outras finalidades (Kim et al., 1999; Khadre et al., 2001; Pang \& Hung, 2016). Tem-se, ainda, que baixas concentrações de ozônio e curto tempo de contato sejam suficientes para inativar bactérias, fungos, leveduras, parasitas e vírus, porém a suscetibilidade dos microrganismos a esse gás varia com o estado fisiológico da cultura, o pH do meio, a temperatura, o teor de água, a carga orgânica, dentre outros fatores (Khadre et al., 2001; Puia et al., 2004; Suslow, 2004; Pascual et al., 2007; Yuk et al., 2007; Akbas \& Ozdemir, 2008; Selma et al., 2008; Pang \& Hung, 2016).

Apesar dos vários trabalhos existentes com o uso do ozônio como agente de conservação de frutas e hortaliças, é necessário estabelecer, para os diferentes alimentos, a melhor combinação de tempo de exposição e concentração deste gás, para que se consiga inativar os microrganismos indesejáveis, minimizando os efeitos indesejáveis na qualidade físico-química do produto. Salienta-se que o ozônio aplicado em altas concentrações - dependendo do período de exposição e da composição química do alimento - pode promover rancidez oxidativa, com expressiva alteração no sabor e na coloração (Kim et al., 1999). Dessa forma, o presente trabalho teve como objetivo avaliar aspectos microbiológicos e físico-químicos de morangos submetidos à ozonização em diferentes concentrações do gás e armazenados durante seis dias sob refrigeração.

\section{Material e métodos}

Utilizaram-se morangos da cultivar Portola, cultivados na cidade de Brazlândia-DF, Brasil. A área de cultivo está localizada a $1.200 \mathrm{~m}$ de altitude e nas coordenadas geográficas de $15^{\circ} 65^{\prime} 25^{\prime \prime}$ de latitude Sul e longitude $48^{\circ} 10^{\prime} 92^{\prime}$ W. Os frutos foram colhidos manualmente em seu ponto de maturação comercial, sendo descartados frutos com lesões.

O gás ozônio foi obtido por meio de um gerador de ozônio (Modelo 0\&L 5.0 RM), baseado no método de descarga por barreira dielétrica (DBD) - efeito corona. No processo de geração do ozônio, foi utilizado, como insumo, oxigênio $\left(\mathrm{O}_{2}\right)$ com grau de pureza de aproximadamente $90 \%$, isento de umidade, obtido de concentrador de oxigênio acoplado ao gerador de ozônio.

Inicialmente, os frutos foram acondicionados em recipientes de vidro com capacidade de 3,2 L, submetidos ao processo de ozonização com o ozônio gasoso. Os morangos foram submetidos ao gás ozônio nas concentrações de $4,9,14$ e $18 \mathrm{mg} \mathrm{L}^{-1}$, vazão de $1 \mathrm{~L} \mathrm{~min}^{-1}$, na temperatura de $25{ }^{\circ} \mathrm{C}$, por $30 \mathrm{~min}$, com três repetições. $\mathrm{O}$ tratamento controle correspondeu aos frutos não ozonizados (concentração $0 \mathrm{mg} \mathrm{L}^{-1}$ ). Após a ozonização, amostras de aproximadamente $200 \mathrm{~g}$ foram colocadas em embalagens retangulares de polietileno tereftalato $(12 \mathrm{~cm} \times 18 \mathrm{~cm} \times 10 \mathrm{~cm})$, transparentes e não herméticas. Posteriormente, as embalagens contendo os frutos foram armazenadas em uma câmara climática tipo B.O.D, na temperatura de $5^{\circ} \mathrm{C}$, com $75 \%$ de umidade relativa. Realizaram-se análises microbiológicas e da qualidade físico-química imediatamente depois da ozonização (dia zero) e a cada dois dias, até o sexto dia de armazenamento. 
Utilizou-se o sistema Petrifilm ${ }^{\mathrm{TM}}$ (3M Company, St. Paul, MN, USA), conforme orientação do fabricante, para contagem de bolores e leveduras (YM), aeróbios mesófilos (AC), coliformes totais e Escherichia coli (EC 6404), adotando-se diluições de $10^{-1}, 10^{-2}, 10^{-3}$ e $10^{-4}$. Destaca-se que essa técnica foi testada em morango fresco por Jordano et al. (1995) para esses microrganismos, obtendo-se resultado satisfatório. Os resultados foram expressos em $\log \left(\mathrm{UFC} \mathrm{g}^{-1}\right)$. Para a detecção de Salmonella spp., utilizou-se a Instrução Normativa número 62, do Ministério da Agricultura, Pecuária e Abastecimento (Brasil, 2003).

$\mathrm{Na}$ avaliação da qualidade físico-química dos morangos, foram avaliados a perda de massa fresca, o pH, a acidez total titulável (ATT), os sólidos solúveis totais (SST), a relação (SST/ATT) e a coloração dos morangos. A perda de massa (PM) foi determinada pela diferença entre a massa fresca inicial e a massa fresca final, com balança digital, sendo expressa em porcentagem. $\mathrm{O} \mathrm{pH}$ foi determinado com o potenciômetro Digimed Mod. DM21. Utilizaram-se aproximadamente $10 \mathrm{~g}$ de amostra triturada e homogeneizada em $100 \mathrm{~mL}$ de água destilada. A ATT foi determinada de acordo com as normas descritas pelo Instituto Adolfo Lutz (2008). Efetuou-se a titulação com solução de hidróxido de sódio $(\mathrm{NaOH}) 0,1 \mathrm{~N}$ padronizada até o ponto de viragem equivalente a pH 8,2, utilizando-se potenciômetro Digimed Mod. DM21. Os resultados foram expressos em porcentagem de ácido cítrico. Os SST foram determinados no refratômetro digital Atago (Modelo 1T). Os resultados foram expressos em ${ }^{\circ}$ Brix, de acordo com a AOAC (Association of Official Analytical Chemists, 2002). A partir dos valores obtidos referentes a SST e ATT, foi possível a obtenção da relação SST/ATT.

A coloração dos morangos foi avaliada usando o colorímetro ColorQuest ${ }^{\circledR}$ XE da HunterLab. O equipamento foi devidamente calibrado e os valores foram tomados da polpa dos frutos, realizando-se duas leituras das amostras de cada repetição. Com os valores das coordenadas $L, a$ e $b$, foi possível obter parâmetros relacionados à saturação da cor ou croma (C) (Equação 1), à tonalidade de cor (h ${ }^{\circ}$ ) (Equação 2) e à diferença de cor ( $\Delta \mathrm{E})$ (Equação 3) (McLellan et al., 1995; Maskan, 2001).

$$
\begin{aligned}
& \mathrm{C}=\sqrt{\left(\mathrm{a}^{2}+\mathrm{b}^{2}\right)} \\
& \mathrm{h}=\operatorname{arctang}(\mathrm{b} / \mathrm{a}) \\
& \Delta \mathrm{E}=\sqrt{\left[\left(\mathrm{L}-\mathrm{L}_{0}\right)^{2}+\left(\mathrm{a}-\mathrm{a}_{0}\right)^{2}+\left(\mathrm{b}-\mathrm{b}_{0}\right)^{2}\right]}
\end{aligned}
$$

Em que:

$\mathrm{a}=$ mensurável em termos de intensidade de vermelho e verde;

$\mathrm{b}=$ mensurável em termos de intensidade de amarelo e azul;

$\mathrm{L}_{0}, \mathrm{a}_{0}$ e $\mathrm{b}_{0}$ são os valores obtidos no tempo zero.

Adotou-se o delineamento inteiramente casualizado nos dois experimentos, em esquema fatorial $5 \times 4$, sendo cinco tratamentos e quatro períodos de armazenamento $(0,2,4$ e 6$)$, com três repetições. Inicialmente, realizou-se análise de variância e, posteriormente, análise de regressão ou teste de média. Utilizou-se o programa estatístico ASSISTAT 7.7 na análise de variância e o software SigmaPlot v. 10 para a obtenção das equações e plotagem dos gráficos.

\section{Resultados e discussão}

Houve diferença significativa na contagem de bolores e de leveduras, e de aeróbios mesófilos, em decorrência da interação entre tratamento e período de armazenamento $(p<0,05)$. Verificou-se, imediatamente depois da ozonização (período zero), contagem de bolores e leveduras inferiores a $1,0 \log \mathrm{UFC} \mathrm{g}^{-1}$ (valores estimados) em todos os tratamentos referentes aos morangos expostos ao gás ozônio, em concentrações entre 4 e $18 \mathrm{mg} \mathrm{L}^{-1}$, por 30 min (Figura 1a e Tabela 1). 
Alves, H. et al.
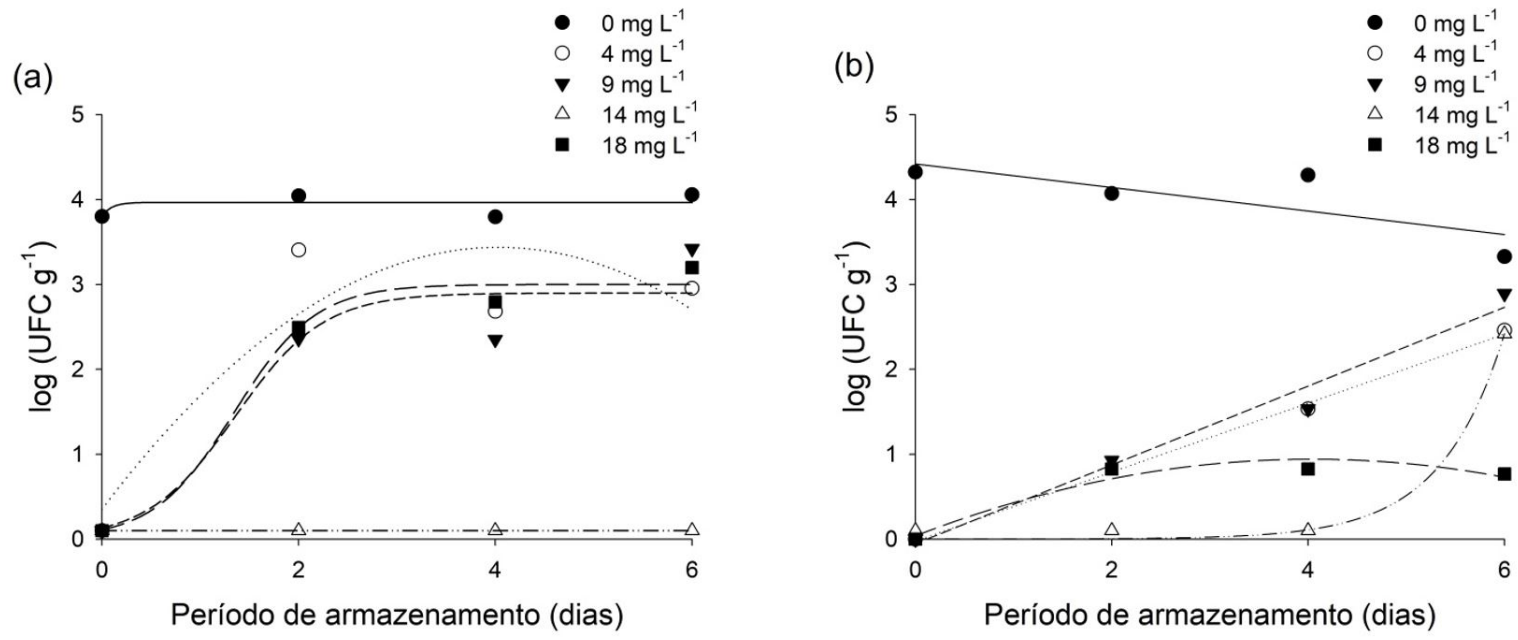

Figura 1. Contagem de bolores e leveduras (a) e aeróbios mesófilos (b) (log UFC g $\left.{ }^{-1}\right)$, em morangos ozonizados em diferentes concentrações do gás e armazenados a $5{ }^{\circ} \mathrm{C}$.

Tabela 1. Equações de regressão ajustadas e respectivos coeficientes de determinação $\left(\mathrm{R}^{2}\right)$ referentes à contagem de bolores e leveduras e de aeróbios mesófilos, em morangos expostos ao gás ozônio em diferentes concentrações e armazenados a $5^{\circ} \mathrm{C}$.

\begin{tabular}{|c|c|c|c|}
\hline Variável & $\begin{array}{l}\text { Concentração } \\
\left(\mathrm{mg} \mathrm{L}^{-1}\right)\end{array}$ & Equações ajustadas & $\mathbf{R}^{2}$ \\
\hline \multirow{5}{*}{ Bolores e Leveduras } & 0 & $\bar{y}=\frac{3,9650}{1+e^{-\left(\frac{x+0,2910}{0,0920}\right)}}$ & 0,32 \\
\hline & 4 & $\bar{y}=0,3510+1,5300 X-0,1900 x^{2}$ & 0,81 \\
\hline & 9 & $\bar{y}=\frac{2,8980}{1+e^{-\left(\frac{x-1,3580}{0,4470}\right)}}$ & 0,90 \\
\hline & 14 & $\bar{y}={ }^{*}$ & 0,00 \\
\hline & 18 & $\bar{y}=\frac{2,9990}{1+e^{-\left(\frac{X-1,3490}{0,4120}\right)}}$ & 0,99 \\
\hline \multirow{5}{*}{ Aeróbios Mesófilos } & 0 & $\bar{y}=4,4180-0,1390 x$ & 0,60 \\
\hline & 4 & $\bar{y}=-0,0230+0,4060 x$ & 0,99 \\
\hline & 9 & $\bar{y}=-0,0550+0,4640 x$ & 0,98 \\
\hline & 14 & $\bar{y}=0,0002^{\star} e^{(1,5488 x)}$ & 0,99 \\
\hline & 18 & $\bar{y}=0,0380+0,4470 X-0,0550 x^{2}$ & 0,99 \\
\hline
\end{tabular}

*Não foram quantificados bolores e leveduras neste tratamento, de acordo com a técnica adotada.

Nos frutos não ozonizados (controle $-0 \mathrm{mg} \mathrm{L}^{-1}$ ), a contagem de bolores e leveduras foi de, aproximadamente, $3,8 \log \mathrm{UFC} \mathrm{g}^{-1}$. Quando se analisou a tendência ao longo do armazenamento por até seis dias, na temperatura de $5{ }^{\circ} \mathrm{C}$, observou-se que, nos frutos não ozonizados, a contagem de bolores e leveduras 
permaneceu em torno de $3,8 \log$ UFC $\mathrm{g}^{-1}$. Com relação aos frutos ozonizados nas concentrações de 4, 9 e $18 \mathrm{mg} \mathrm{L}^{-1}$, houve incremento na contagem de bolores e leveduras, à medida que se elevou o período de armazenamento. Deve-se destacar que, apesar disso, a contagem de bolores e leveduras nos frutos ozonizados permaneceu inferior aos valores obtidos naqueles não ozonizados (controle $-0 \mathrm{mg} \mathrm{L}^{-1}$ ). Quando se adotaram as concentrações de 9 e $18 \mathrm{mg} \mathrm{L}^{-1}$, obtiveram-se diferenças estimadas em relação ao tratamento controle, respectivamente, iguais a 1,07 e $0,97 \log \mathrm{UFC} \mathrm{g}^{-1}$, aos seis dias de armazenamento. No que tange aos frutos ozonizados na concentração de $14 \mathrm{mg} \mathrm{L}^{-1}$, não foi possível a quantificação de bolores e leveduras por até seis dias de armazenamento, de acordo com a técnica adotada. A presença de bolores e leveduras nos frutos ozonizados na concentração de $18 \mathrm{mg} \mathrm{L}^{-1}$, diferentemente do observado quando se adotou a concentração de $14 \mathrm{mg} \mathrm{L}^{-1}$, pode ser explicada pelo fato de que concentrações muito elevadas podem alterar as características do produto, podendo inclusive favorecer o crescimento de microrganismos (Alencar et al., 2013).

A ozonização se mostrou eficiente na inativação de aeróbios mesófilos, quando se adotaram concentrações na faixa entre 4 e $18 \mathrm{mg} \mathrm{L}^{-1}$, por $30 \mathrm{~min}$ (Figura $1 \mathrm{~b}$ e Tabela 1). Imediatamente depois da ozonização, foi possível obter redução superior a 4,0 ciclos log na contagem de mesófilos aeróbios, quando se compararam os resultados obtidos nos frutos ozonizados com aqueles obtidos ao analisar os frutos não expostos ao gás. Durante o armazenamento por até seis dias, houve incremento da contagem de mesófilos aeróbios nos frutos submetidos à ozonização, porém os valores permaneceram inferiores aos obtidos nos frutos não ozonizados (controle $-0 \mathrm{mg} \mathrm{L}^{-1}$ ). Os resultados indicaram que é possível inibir satisfatoriamente o desenvolvimento de mesófilos aeróbios por até quatro dias, quando se adotam concentrações do ozônio de 4,9 e $14 \mathrm{mg} \mathrm{L}^{-1}$. Para concentrações equivalentes a 4,9 e $14 \mathrm{mg} \mathrm{L}^{-1}$, as diferenças estimadas em relação ao tratamento controle, no quarto dia de armazenamento, foram equivalentes a 2,26, 2,06 e 3,76 log UFC g ${ }^{-1}$, respectivamente. Depois de seis dias de armazenamento, verificou-se menor contagem de mesófilos aeróbios nos frutos ozonizados na concentração de $18 \mathrm{mg} \mathrm{L}^{-1}$, permanecendo inferior a $1,00 \log \mathrm{UFC} \mathrm{g}^{-1}$ (valor estimado), enquanto que o equivalente para os frutos não ozonizados foi de $3,58 \log \mathrm{UFC} \mathrm{g}^{-1}$.

A inativação de microrganismos pelo ozônio, segundo Cullen et al. (2009), é atribuída, principalmente, à ruptura do envoltório celular e posterior dispersão dos constituintes citoplasmáticos, uma vez que esse gás apresenta alto poder oxidante. Victorin (1992) relatou que existem dois mecanismos do ozônio na destruição de biomoléculas: como primeiro mecanismo, o ozônio oxida grupos sulfidrila e aminoácidos de enzimas, proteínas e peptídeos, e como segundo mecanismo, ocorre a ação do gás como agente oxidante de ácidos graxos poli-insaturados a peroxiácidos. Essa capacidade do ozônio de inativar ou inibir o desenvolvimento dos microrganismos é fundamental sob o ponto de vista de segurança dos alimentos, pois pode representar uma forma de controle de diferentes espécies de microrganismos, especialmente os patogênicos.

Não foram detectados Salmonella spp. e quantificados E. coli nos morangos submetidos ou não à ozonização. Com relação à contagem de coliformes totais, apesar de terem sido quantificados, os dados não são conclusivos, uma vez que nem todas as amostras apresentavam esse grupo de microrganismos. Dessa forma, não foi possível inferir sobre a capacidade do ozônio de inativar Salmonella spp., coliformes totais e E. coli em morangos, no presente trabalho. Entretanto, Pang \& Hung (2016) demonstraram que uma combinação de radiação UV e água ozonizada foi capaz de alcançar uma redução em torno de 5,00 ciclos log na contagem de E. coli $\mathrm{O} 157: \mathrm{H} 7$, em alface romana, enquanto os tratamentos com radiação UV e água ozonizada, isoladamente, possibilitaram reduções de 2,10 e 2,70 ciclos log, respectivamente.

Não foi observada variação significativa $(p>0,05)$ em decorrência da interação entre tratamento e período de armazenamento para as variáveis perda de massa, $\mathrm{pH}$, SST ( ${ }^{\circ}$ Brix), relação SST/ATT e coloração dos frutos (saturação e tonalidade de cor). Entretanto, houve variação significativa $(p<0,05)$ para essas variáveis quando se analisou o efeito da exposição ao ozônio e do período de armazenamento, separadamente. Na Tabela 2, são apresentados os valores médios referentes à perda de massa, ao $\mathrm{pH}$, aos sólidos solúveis totais (SST), à relação entre SST e acidez total titulável (ATT) e à tonalidade de cor nos frutos submetidos a diferentes concentrações do gás ozônio, independentemente do período de armazenamento. 
Tabela 2. Valores médios de perda de massa (PM), pH, sólidos solúveis totais (SST, ${ }^{\circ}$ Brix), relação entre SST e acidez total titulável (ATT) e a tonalidade de cor $\left(\mathrm{h}^{\circ}\right)$ nos frutos submetidos a diferentes concentrações do ozônio, independentemente do período de armazenamento.

\begin{tabular}{|c|c|c|c|c|c|}
\hline \multirow{2}{*}{ Variável } & \multicolumn{5}{|c|}{ Concentração do ozônio } \\
\hline & $0 \mathrm{mg} \mathrm{L}^{-1}$ & $4 \mathrm{mg} \mathrm{L}^{-1}$ & $9 \mathrm{mg} \mathrm{L}^{-1}$ & $14 \mathrm{mg} \mathrm{L}^{-1}$ & $18 \mathrm{mg} \mathrm{L}^{-1}$ \\
\hline PM (\%) & $4,23 \pm 4,51 \mathrm{a}$ & $3,56 \pm 2,38 \mathrm{ab}$ & $2,30 \pm 2,33 b$ & $2,98 \pm 2,58 \mathrm{ab}$ & $1,83 \pm 1,60 b$ \\
\hline $\mathrm{pH}$ & $3,52 \pm 0,11 \mathrm{ab}$ & $3,57 \pm 0,10 \mathrm{a}$ & $3,50 \pm 0,06 a b$ & $3,55 \pm 0,08 \mathrm{ab}$ & $3,47 \pm 0,14 b$ \\
\hline SST ( $\left.{ }^{\circ} \mathrm{BRIX}\right)$ & $7,85 \pm 0,30 b$ & $8,69 \pm 1,10 a$ & $8,08 \pm 0,36 \mathrm{ab}$ & $8,10 \pm 0,49 \mathrm{ab}$ & $8,19 \pm 0,18 \mathrm{ab}$ \\
\hline SST/ATT & $9,59 \pm 0,99 b$ & $10,75 \pm 1,25 \mathrm{a}$ & $9,83 \pm 0,65 \mathrm{ab}$ & $10,09 \pm 0,50 \mathrm{ab}$ & $9,80 \pm 0,57 \mathrm{ab}$ \\
\hline Tonalidade $\left(\mathrm{h}^{\circ}\right)$ & $30,58 \pm 3,07 \mathrm{ab}$ & $29,83 \pm 4,09 b$ & $31,17 \pm 3,37 \mathrm{a}$ & $30,93 \pm 3,44 \mathrm{ab}$ & $30,67 \pm 3,47 \mathrm{ab}$ \\
\hline
\end{tabular}

Valores seguidos de mesma letra na linha não diferem estatisticamente entre si pelo Teste de Tukey a $5 \%$ de probabilidade.

Observou-se tendência de redução da perda de massa nos frutos à medida que se elevou a concentração do gás. O percentual de perda de massa (PM) nos frutos não ozonizados (controle $-0 \mathrm{mg} \mathrm{L}^{-1}$ ) foi de 4,23\%, enquanto que naqueles ozonizados, na concentração de $18 \mathrm{mg} \mathrm{L}^{-1}$, foi de 1,83\%. Apesar de ter sido verificada diferença significativa na variável $\mathrm{pH}$, não foi possível relacioná-la com a ozonização, sendo que os valores permaneceram em torno de 3,50. No que se refere às variáveis SST e relação SST/ATT, destaca-se a diferença significativa observada somente quando se compararam os valores médios obtidos nos frutos não ozonizados com aqueles obtidos no produto ozonizado na concentração de $4 \mathrm{mg} \mathrm{L}^{-1}$. Foram obtidos maiores valores médios de SST e relação SST/ATT nos frutos ozonizados, equivalentes a $8,69^{\circ}$ Brix e 10,75 , respectivamente. Nos frutos não ozonizados, os valores médios de SST e relação SST/ATT foram iguais e a 7,85 ${ }^{\circ}$ Brix e 9,59, respectivamente.

No que tange à perda de massa (PM) em função do período de armazenamento (Figura 2a), independentemente da exposição ao gás ozônio, a tendência observada está de acordo com o esperado, ou seja, incremento da perda de massa à medida que se eleva o período de armazenamento. Simão \& Rodríguez (2009) avaliaram a perda de massa em tomates e constataram que, com a ozonização, as perdas de massa foram reduzidas em aproximadamente 50\% durante armazenamento. Zhang et al. (2011) observaram diminuição significativa na perda de massa de morangos ao longo de 20 dias de armazenamento ao se utilizar uma concentração de gás ozônio de 4 ppm. Outros relatos encontrados na literatura indicam que o ozônio pode afetar a atividade respiratória e, consequentemente, a perda de massa, dependendo da concentração e do período de exposição ao gás (Liew \& Prange, 1994; Palou et al., 2002). É importante mencionar o possível efeito da umidade relativa (75\%) no interior da câmara climática na qual os frutos foram acondicionados, uma vez que o acondicionamento dos frutos nas embalagens não foi hermético. De acordo com resultados obtidos por Shin et al. (2008), a umidade relativa é determinante na perda de massa de morangos, porém possui pouco efeito em variáveis como firmeza e cor. 
(a)

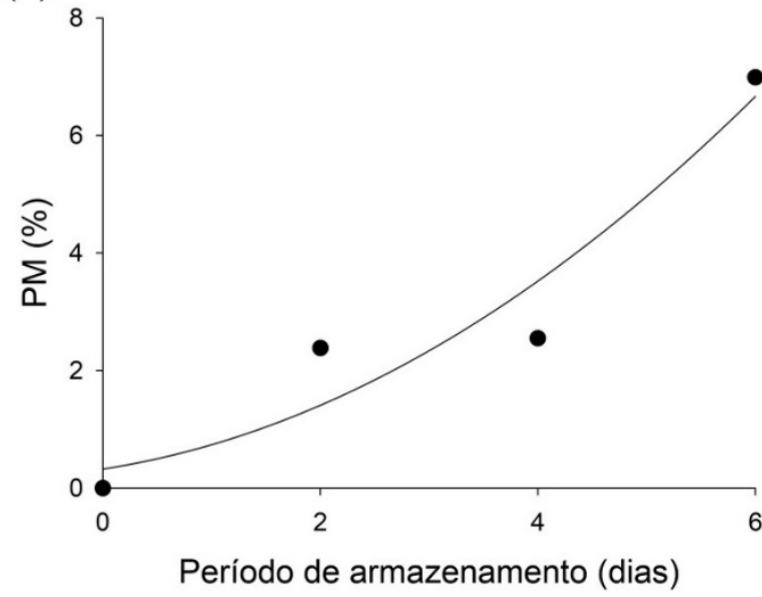

(c)

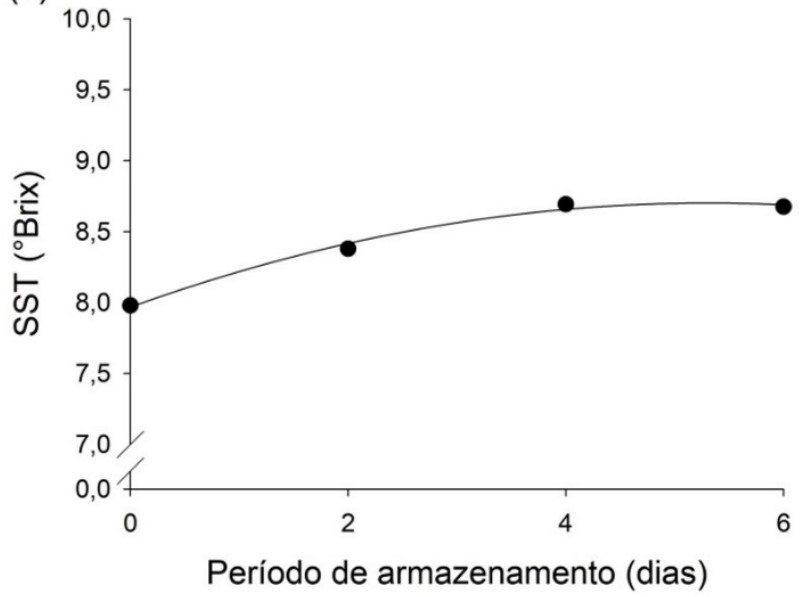

(e)

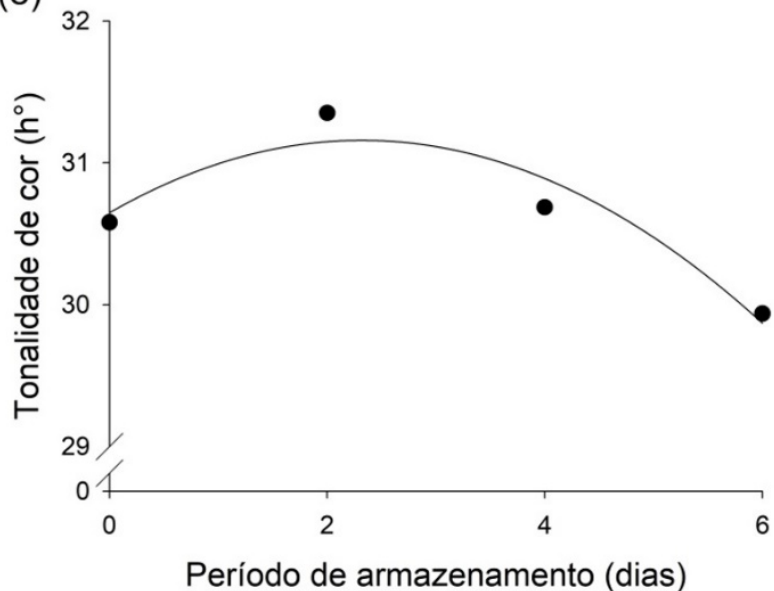

(b)

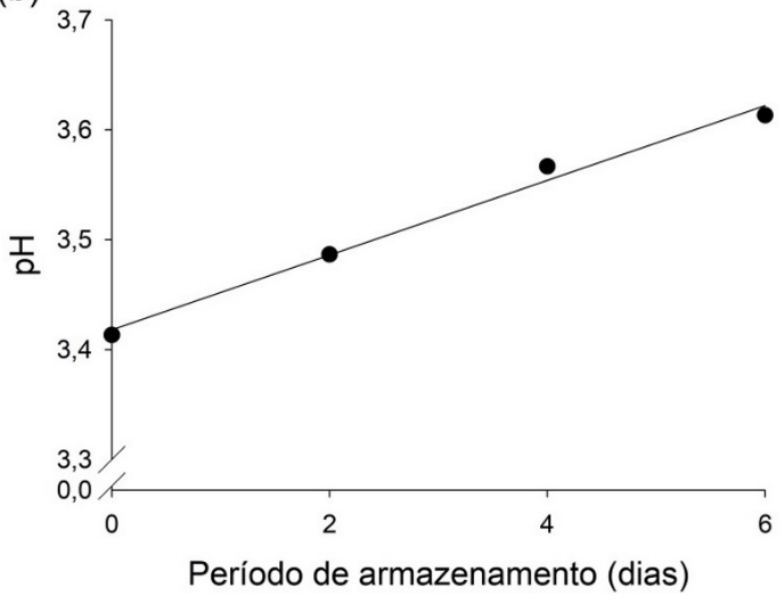

(d)

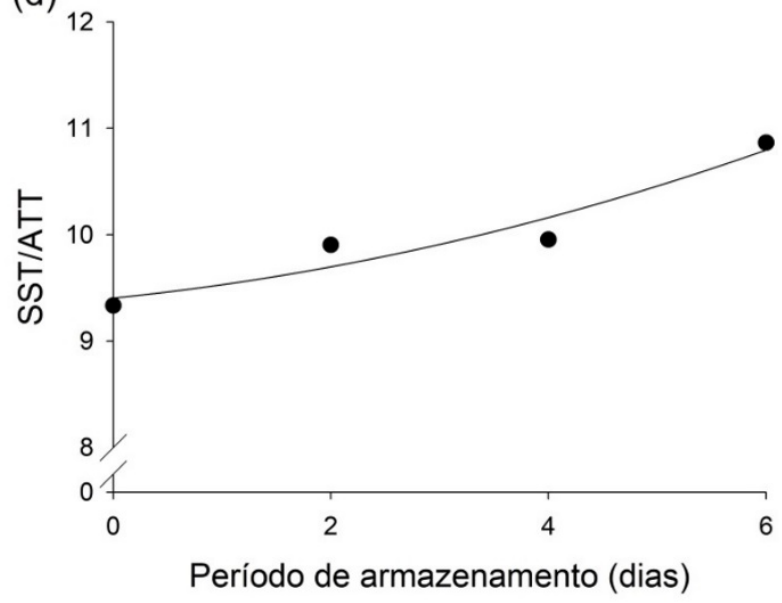

(f)

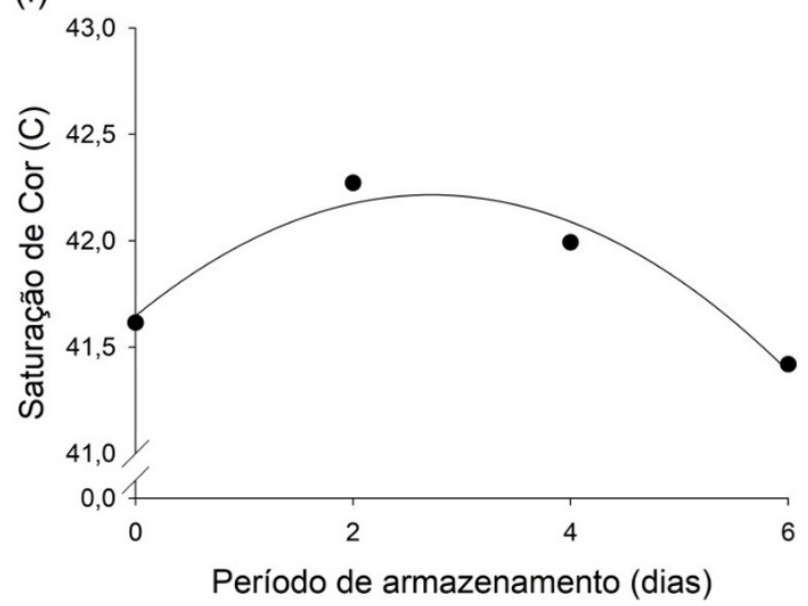

Figura 2. Curvas de regressão em função do período de armazenamento para perda de massa (PM) (a), pH (b), Sólidos Solúveis Totais (SST) (c), relação entre SST e acidez total titulável (ATT) (d), Tonalidade $\left(\mathrm{h}^{\circ}\right)$ (e) e Saturação (C) (f) de cor em morangos. $\overline{\mathrm{y}} \mathrm{PM}=0,324+0,286 \mathrm{X}+0,129 \mathrm{X}^{2} \mathrm{R}^{2}=0,92 ; \overline{\mathrm{y}}_{\mathrm{pH}}=3,418+0,034 \mathrm{X} \mathrm{R}^{2}=0,99 ; \overline{\mathrm{y}} \mathrm{ssT}=7,968+0,276 \mathrm{X}-0,026 \mathrm{X}^{2}$ $\mathrm{R}^{2}=0,99 ; \overline{\mathrm{y}}_{\mathrm{SST} / \mathrm{ATT}}=9,403+0,104 \mathrm{X}+0,021 \mathrm{X}^{2} \mathrm{R}^{2}=0,92 ; \overline{\mathrm{y}}_{\mathrm{h}^{\circ}}=30,648+0,440 \mathrm{X}-0,095 \mathrm{X}^{2} \mathrm{R}^{2}=0,91 ; \overline{\mathrm{y}}_{\mathrm{C}}=$ $41,647+0,418 X-0,077 X^{2} R^{2}=0,95$.

Observou-se ligeiro incremente durante o armazenamento nas variáveis pH e SST, respectivamente (Figuras $2 \mathrm{~b}$ e 2c). Os sólidos solúveis totais (SST) nos frutos permaneceram na faixa entre 8,00 e 8,60 ${ }^{\circ} \mathrm{Brix}$, 
Alves, $H$. et al.

enquanto que o $\mathrm{pH}$ variou entre 3,40 e 3,65. No que se refere ao $\mathrm{pH}$, Holtz (2006) encontrou resultados diferentes para morangos minimamente processados, observando decréscimos nos valores de $\mathrm{pH}$ nos morangos tratados com ozônio. Na Figura 2d, é apresentada a curva na qual se tem a relação SST/ATT em função do período de armazenamento. Verificou-se incremento dessa variável à medida que se elevou o período de armazenamento, sendo que essa relação permaneceu na faixa entre 9,3 e 10,9. As curvas de regressão de tonalidade de cor $\left(\mathrm{h}^{\circ}\right)$ e saturação de cor (croma) de morangos, independentemente da ozonização, em função do período de armazenamento, são apresentadas nas Figuras $2 \mathrm{e}$ e $2 \mathrm{f}$, respectivamente. Para ambas as variáveis, observou-se tendência de incremento até o segundo dia de armazenamento, com posterior decréscimo.

Obteve-se diferença significativa $(p<0,05)$ para as variáveis acidez total titulável (ATT) (Figura 3a), e Diferença de cor $(\Delta \mathrm{E})$ (Figura $3 \mathrm{~b})$, em decorrência da interação entre tratamento e período de armazenamento em morangos submetidos à ozonização em diferentes concentrações e armazenados a $5{ }^{\circ} \mathrm{C}$ por seis dias. $\mathrm{Na}$ Tabela 3, constam as equações de regressão ajustadas e respectivos coeficientes de determinação $\left(\mathrm{R}^{2}\right)$ para acidez total titulável e diferença de cor.
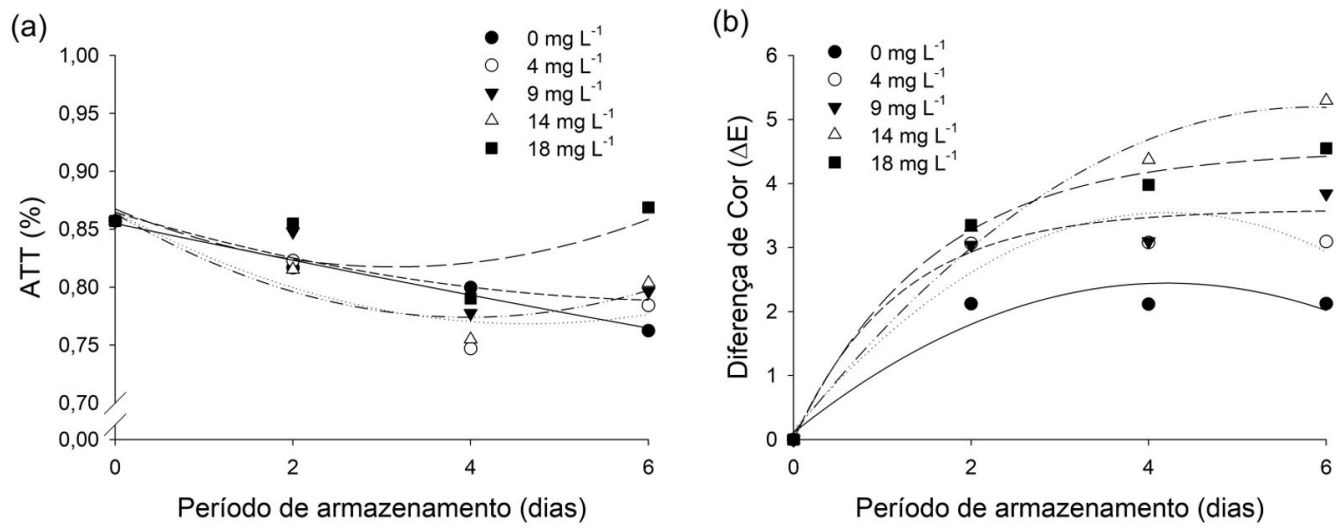

Figura 3. Acidez total titulável (ATT) (a) e Diferença de cor $(\Delta \mathrm{E})(\mathrm{b})$ em morangos submetidos à ozonização em diferentes concentrações e armazenados a $5{ }^{\circ} \mathrm{C}$ por seis dias.

Tabela 3. Equações de regressão ajustadas e respectivos coeficientes de determinação $\left(\mathrm{R}^{2}\right)$ para acidez total titulável (ATT) e diferença de cor $(\Delta \mathrm{E})$ em morangos expostos ao gás ozônio em diferentes concentrações e armazenados a $5^{\circ} \mathrm{C}$.

\begin{tabular}{|c|c|c|c|}
\hline Variável & $\begin{array}{c}\text { Tratamento } \\
\left(\mathrm{mg} \mathrm{L}^{-1}\right)\end{array}$ & Equações ajustadas & $\mathbf{R}^{2}$ \\
\hline \multirow{5}{*}{ ATT (\%) } & 0 & $\bar{y}=0,855-0,016 x$ & 0,98 \\
\hline & 4 & $\bar{y}=0,865-0,042 X+0,005 x^{2}$ & 0,82 \\
\hline & 9 & $\bar{y}=0,865-0,023 X+0,002 x^{2}$ & 0,75 \\
\hline & 14 & $\bar{y}=0,864-0,045 X+0,006 x^{2}$ & 0,85 \\
\hline & 18 & $\bar{y}=0,867-0,032 X+0,005 x^{2}$ & 0,44 \\
\hline \multirow{5}{*}{$\Delta \mathrm{E}$} & 0 & $\bar{y}=0,107+1,111 X-0,132 x^{2}$ & 0,93 \\
\hline & 4 & $\bar{y}=0,1525+1,608 X-0,191 x^{2}$ & 0,93 \\
\hline & 9 & $\bar{y}=3,591\left(1-e^{(-0,846 X)}\right)$ & 0,97 \\
\hline & 14 & $\bar{y}=4,519\left(1-e^{(-0,644 x)}\right)$ & 0,99 \\
\hline & 18 & $\bar{y}=0,106+1,742 X-0,149 x^{2}$ & 0,96 \\
\hline
\end{tabular}


Os valores estimados de acidez total titulável (ATT) nos frutos não ozonizados e naqueles ozonizados na concentração de $18 \mathrm{mg} \mathrm{L}^{-1}$ foram 0,76 e 0,86 , respectivamente, depois de seis dias de armazenamento. Segundo Chitarra \& Chitarra (2005), ocorre diminuição da acidez com o amadurecimento dos frutos, pois os ácidos orgânicos voláteis e não voláteis estão entre os constituintes celulares mais metabolizados no processo de amadurecimento. Todavia, os resultados encontrados neste experimento foram diferentes dos obtidos por Nadas et al. (2003) e Rahman (2016), que não mostraram diferenças significativas para acidez total titulável em decorrência da ozonização.

Verificou-se aumento da diferença de cor $(\Delta \mathrm{E})$ à medida que se elevou o período de armazenamento, porém essa tendência foi menos acentuada nos morangos não ozonizados (controle) (Figura 3b). Ressalta-se que a variável diferença de cor foi obtida a partir dos valores de $L, a$ e $b$, em um determinado período de armazenamento e de valores correspondentes a um padrão, os quais, no presente trabalho, referiram-se aos frutos no início do armazenamento. Dessa forma, uma maior elevação da diferença de cor implica em um distanciamento mais pronunciado da cor inicial, comportamento observado nos morangos ozonizados à medida que aumentou a concentração do gás. Simão \& Rodríguez (2009), em sua pesquisa com tomates, somente observaram ligeira alteração na diferença de cor quando, a partir do sétimo dia, compararam os resultados com os obtidos no grupo controle.

Outras alterações que são de extrema relevância e que não foram abordadas no presente estudo são referentes à qualidade sensorial de produtos ozonizados. Entretanto, outros autores pesquisaram a aceitação de frutos ozonizados e não verificaram alterações indesejáveis. Selma et al. (2008) não obtiveram alterações significativas na qualidade sensorial em melão exposto ao ozônio na concentração de 10.000 ppm/30 min. Onopiuk et al. (2017) observaram que concentração do ozônio de até $0,9 \mathrm{mg} \mathrm{L}^{-1}$, por até $120 \mathrm{~min}$, não afetou os atributos sensoriais de framboesa.

\section{Conclusões}

A análise e a interpretação dos dados permitiram concluir que a ozonização foi eficaz no controle de aeróbios mesófilos, com destaque para concentração de $18 \mathrm{mg} \mathrm{L}^{-1}$. As demais concentrações possibilitaram diferença superior a 2,0 $\log$ UFC g-1 , por até quatro dias, em relação ao tratamento controle. Quanto aos bolores e leveduras, a concentração de $14 \mathrm{mg} \mathrm{L}^{-1}$ foi a que se mostrou eficiente no controle desses microrganismos. Nas condições adotadas no presente trabalho, em geral, a ozonização não interferiu negativamente nas variáveis físico-químicas avaliadas, tais como perda de massa fresca, níveis de $\mathrm{pH}$, sólidos solúveis, acidez titulável, relação SS/AT e naquelas referentes à cor do produto.

\section{Agradecimentos}

À Coordenação de Aperfeiçoamento de Pessoal de Nível Superior (CAPES), pela bolsa de estudos, e ao CNPq e à Fundação de Apoio à Pesquisa do Distrito Federal (FAPDF), pelo apoio financeiro.

\section{Referências}

Abadias, M., Usall, J., Anguera, M., Solsona, C., \& Viñas, I. (2008). Microbiological quality of fresh, minimally-processed fruit and vegetables, and sprouts from retail establishments. International Journal of Food Microbiology, 123(2), $121-129$. PMid:18237811.

Aguayo, E., Jansasithorn, R., \& Kader, A. A. (2006). Combined effects of 1-methylcyclopropene, calcium chloride dip, and/or atmospheric modification on quality changes in fresh-cut strawberries. Postharvest Biology and Technology, 40, $269-278$.

Akbas, M. Y., \& Ozdemir, M. (2008). Application of gaseous ozone to control populations of Escherichia coli, Bacillus cereus and Bacillus cereus spores in dried figs. Food Microbiology, 25(2), 386-391. PMid:18206781.

Alencar, E. R., Faroni, L. R. D., Pinto, M. S., \& Costa, A. R. (2013). Postharvest quality of ozonized 'nanicão' cv. bananas Revista Ciência Agronômica, 44(1), 107-114. http://dx.doi.org/10.1590/S1806-66902013000100014. 
Alves, H. et al.

Alexandre, E. M. C., Pedro, D. M. S., Brandão, T. R. S., \& Silva, C. L. M. (2011). Influence of aqueous ozone, blanching and combined treatments on microbial load of red bell peppers, strawberries and watercress. Journal of Food Engineering, 105(1), 277-282.

Association of Official Analytical Chemists - AOAC. (2002). Official methods of analysis of the Association of Official Analytical Chemists (17th ed.). Maryland: AOAC.

Brasil. (2003, setembro 18). Dispõe sobre os métodos analíticos oficiais para análises microbiológicas para controle de produtos de origem animal e água (Instrução Normativa SDA nº 62, de 26 de agosto de 2003). Diário Oficial [da] República Federativa do Brasil, Brasília.

Chiattone, P. V., Torres, L. M., \& Zambiazi, R. C. (2008). Aplication of ozone in industry of food. Alimentos e Nutrição, 19(1), 341-349.

Chitarra, M. I. F., \& Chitarra, A. B. (2005). Pós-colheita de frutas e hortaliças: fisiologia e manuseio (2. ed., 785 p.). Lavras: UFLA.

Coelho, C. C. S., Silva, O. F., Alcantara, I., Silva, J. P. L., \& Cabral, L. M. C. (2015). Ozonização como tecnologia pós-colheita na conservação de frutas e hortaliças: Uma revisão. Revista Brasileira de Engenharia Agrícola e Ambiental, 19(4), 369-375.

Cullen, P. J., Tiwari, B. K., O'Donnell, C. P., \& Muthukumarappan, K. (2009). Modelling approaches to ozone processing of liquid foods. Trends in Food Science \& Technology, 20, 125-136.

Food and Drug Administration - FDA. (2001). Secondary direct food additives permitted in food for human consumption Federal Register, 66(123), 33829-33830.

Food and Drug Administration - FDA. (2013). Direct food substances affirmed as generally recognized as safe. Recuperado em 21 de setembro de 2017, de http://www.accessdata.fda.gov/scripts/cdrh/cfdocs/cfcfr/CFRSearch.cfm?fr=184.1563

Graham, D. M. (1997). Use of ozone for food processing. Food Technology, 51(6), 72-75.

Güzel-Seydim, Z., Greene, A. K., \& Seydim, A. C. (2004). Use of ozone in the food industry. Lebensmittel-Wissenschaft + Technologie, 37(1), 453-460.

Holtz, S. G. (2006). Aplicação de ozônio e de revestimentos comestíveis em morangos (Fragaria ananassa Duch.) minimamente processados (Dissertação de mestrado). Universidade Federal de Viçosa, Viçosa.

Instituto Adolfo Lutz - IAL. (2008). Métodos físico-químicos para análise de alimentos (4. ed.). São Paulo: IAL.

Jordano, R., Lopez, C., Rodriguez, V., Cordoba, G., Medina, L. M., \& Barrios, J. (1995). Comparison of Petrifilm method to conventional methods for enumerating aerobic bacteria, coliforms, Escherichia coli and yeasts and molds in foods. Acta Microbiologica et Immunologica Hungarica, 42(3), 255-259. PMid:8548198.

Khadre, M. A., Yousef, A. E., \& Kim, J. G. (2001). Microbiological aspects of ozone applications in food: a review. Journal of Food Science, 66(9), 1242-1252. http://dx.doi.org/10.1111/j.1365-2621.2001.tb15196.x.

Kim, J. G., Yousef, A. E., \& Dave, S. (1999). Application of ozone for enhancing the microbiological safety and quality of foods: a review. Journal of Food Protection, 62(9), 1077-1087. PMid:10492485.

Liew, C. L., \& Prange, R. K. (1994). Effect of ozone and storage temperature on postharvest diseases and physiology of carrots (Daucus carota L.). Journal of the American Society for Horticultural Science, 119(3), 563-567.

Maskan, M. (2001). Kinetics of colour change of kiwifruits during hot air and microwave drying. Journal of Food Engineering, 48, 169-175.

McLellan, M. R., Lind, L. R., \& Kime, R. W. (1995). Hue angle determinations and stastistical analysis for multiquadrant hunter L, a, b data. Journal of Food Quality, 18(3), 235-240. http://dx.doi.org/10.1111/j.1745-4557.1995.tb00377.x.

Mendez, F., et al (2003). Penetration of ozone into columns of stored grains and effects on chemical composition and performance. Journal of Stored Products Research, 39(1), 33-44.

Nadas, A., Olmo, M., \& García, J. M. (2003). Growth of Botrytis cinerea and strawberry quality in ozone enriched atmospheres. Journal of Food Science, 68(5), 1798-1802.

Nascimento, M. S., \& Silva, N. (2010). Tratamentos químicos na sanitização de morango (Fragaria vesca L). Brazilian Journal of Food Technology, 13(1), 11-17.

Notermans, S., Znadvoort-Roelofsen, J. S. V., Barendsz, A. W., \& Beczner, J. (2004). Risk profile for strawberries. Food Protection Trends, 24(10), 730-739.

Onopiuk, A., Półtorak, A., Moczkowska, M., Szpicer, A., \& Wierzbicka, A. (2017). The impact of ozone on health-promoting microbiological, and colour properties of Rubus ideaus raspberries. CYTA: Journal of Food, 15(4), 563-573.

Palou, L., Crisosto, C. H., Smilanick, J. L., Adaskaveg, J. E., \& Zoffoli, J. P. (2002). Effects of continuous 0.3 ppm ozone exposure on decay development and physiological responses of peaches and table grapes in cold storage. Postharvest Biology and Technology, 24(1), 39-48.

Pang, Y. H., \& Hung, Y. C. (2016). Efficacy of slightly acidic electrolyzed water and UV-ozonated water combination for inactivating Escherichia coli O157:H7 on romaine and iceberg lettuce during spray washing process. Journal of Food Science, 81(7), M1743-1748. PMid:27305593.

Pascual, A., Llorca, L., \& Canut, A. (2007). Use of ozone in food industries for reducing the environmental impact of cleaning and disinfection activities. Trends in Food Science \& Technology, 18(1), 29-35. 
Alves, H. et al.

Ponce, A., Bastiani, M. I. D., Minim, V. P., \& Vanetti, M. C. D. (2010). Características físico-químicas e microbiológicas de morango minimamente processado. Food Science and Technology (Campinas), 30(1), 113-118. http://dx.doi.org/10.1590/S0101-20612010005000016.

Puia, C., Oroian, I., \& Florian, V. (2004). Effect of ozone exposure on phytopathogenic microorganisms on stored apples. Journal of Agricultural Sciences, 15(1), 9-13.

Rahman, M. M. (2016). Determination of maturity indices of strawberry in Dhaka, Bangladesh. Bangladesh Journal of Botany, 45(5), 1127-1134.

Selma, M. V., Ibáñez, A. M., Allende, A., Cantwell, M., \& Suslow, T. (2008). Effect of gaseous ozone and hot water on microbial and sensory quality of cantaloupe and potential transference of Escherichia coli 0157:H7 during cutting. Food Microbiology 25(1), 162-168. PMid:17993390.

Shin, Y., Ryu, J., Liu, R. H., Nock, J. F., \& Watkins, C. B. (2008). Harvest maturity, storage temperature and relative humidity affect fruit quality, antioxidant contents and activity, and inhibition of cell proliferation of strawberry fruit. Postharvest Biology and Technology, 49(2), 201-209.

Silva, S. B., Luvielmo, M. M., Geyer, M. C., \& Prá, I. (2011). Potencialidades do uso do ozônio no processamento de alimentos. Semina: Ciências Agrárias, 32(2), 659-682.

Simão, R., \& Rodríguez, T. D. M. (2009). Utilização do ozônio no tratamento pós-colheita do tomate (Lycopersicon esculentum Mill). Revista de Estudios Sociales, 11(22), 115-124.

Sivapalasingam, S., Friedman, C. R., Cohen, L., \& Tauxe, R. V. (2004). Fresh produce: a growing cause of outbreaks of foodborne illness in the United States, 1973 through 1997. Journal of Food Protection, 67(10), 2342-2353. PMid:15508656.

Suslow, T. V. (2004). Ozone applications for postharvest disinfection of edible horticultural crops. Division of Agriculture and Natural Resources, 8133(1), 1-8.

Tournas, V. H., \& Katsoudas, E. (2005). Mould and yeast flora in fresh berries, grapes and citrus fruits. International Journal of Food Microbiology, 105(1), 11-17. PMid:16023239.

Victorin, K. (1992). Review of genotoxicity of ozone. Mutation Research, 277(3), 221-238. PMid:1381051.

Yuk, H. G., Yoo, M. Y., Yoon, J. W., Marshall, D. L., \& Oh, D. H. (2007). Effect of combined ozone and organic acid treatment for control of Escherichia coli 0157:H7 and Listeria monocytogenes on enoki mushroom. Food Control, 18(1), 548-553.

Zhang, X., Zhang, Z., Wang, L., Zhang, Z., Li, L., \& Zhao, C. (2011). Impact of ozone on quality of strawberry during cold storage. Frontiers of Agriculture in China, 5(3), 356-360.

Financiamento: Coordenação de Aperfeiçoamento de Pessoal de Nível Superior - CAPES (Código de Financiamento 001); Conselho Nacional de Desenvolvimento Científico e Tecnológico - CNPq (Processo n 447840-2014-2); e Fundação de Apoio à Pesquisa do Distrito Federal - FAPDF (Processo $n^{\circ}$ 0193.001069/2015). 